\title{
Mehr Kontrolle bei Milchkühen!
}

\section{Prozent der Milchkühe erhalten Antibiotika, jede zehnte Behandlung sogar mit Reserveantibiotika. Nun hagelt es Kritik für die Politik.}

Der Einsatz von Antibiotika bei Milchkühen wird aus Sicht der Umweltorganisation Germanwatch unzureichend überwacht. Bislang müssten nur Fleischerzeuger dokumentieren, wie oft sie Antibiotika einsetzen, sagte die Germanwatch-Agrarexpertin Reinhild Benning. Nach ihren Recherchen erhalten Kühe pro Jahr 1,5 bis 3,3 Mal Antibiotika. „Das sind besorgniserregende Werte, die wachrütteln sollten“, so Benning. Zahlen des Bundesamtes für Verbraucherschutz und Lebensmittelsicherheit (BVL) zeigen, dass rund $80 \%$ der Milchkühe in Deutschland Antibiotika vor der Geburt des jeweils nächsten Kalbes erhalten. Jede zehnte Behandlung erfolgt sogar mit Reserveantibiotika.

Von der Milch selbst gehe aufgrund des Einsatzes in direkter Folge zwar kein gesundheitliches Risiko aus, „besorgniserregend" sei jedoch, dass die Entwicklung resistenter Keime begünstigt werde. Ursache des Problems sei, dass Bauern aus wirtschaftlichem Druck mehr Tiere als früher halten und ihnen mehr Leistung abverlangen müssten.

\section{Gefahr von Antibiotika-Resistenzen}

Germanwatch fordert von Bundeslandwirtschaftsminister Christian Schmidt (CSU) deshalb einen Systemwechsel in der Tierhaltung, damit Antibiotika nicht mehr systematisch, sondern allenfalls in Einzelfällen gebraucht werden. Zudem müsse der Minister zügig die Forderungen des Bundesrates nach sehr strengen Regeln gegen unkontrollierten Einsatz und Missbrauch von Reserveantibiotika im Stall umsetzen.

Erst vor Kurzem war bekannt geworden, dass auch hierzulande eine neuartige Resistenz gegen das wichtige Notfall-Antibiotikum Colistin nachgewiesen wurde. Der Nutztierexperte der Gesellschaft für Ganzheitliche Tiermedizin (GGTM), Tierarzt Dr. Andreas Striezel, kritisiert: „Das Bundeslandwirtschaftsministerium hat seit Monaten versäumt, wirkungsvolle Maßnahmen gegen den zu hohen und zum Teil steigenden Einsatz von Reserveantibiotika zu ergreifen."

Das bisherige Erfassungssystem in der Antibiotika-Datenbank sei nicht ausreichend, da die Meldungen über Antibiotikaeinsätze unvollständig seien und Milchkühe sowie viele andere Tiergruppen nicht erfasst würden.

Das Bundesinstitut für Risikobewertung (BfR) hatte im November 2015 hingegen eine Erhebung veröffentlicht, die positive Tendenzen in der Nutztierhaltung insgesamt ausweist: Dem Forschungsprojekt zufolge wurden etwa Mastschweinen in den vergangenen Jahren deutlich weniger Antibiotika gegeben.

(jk)

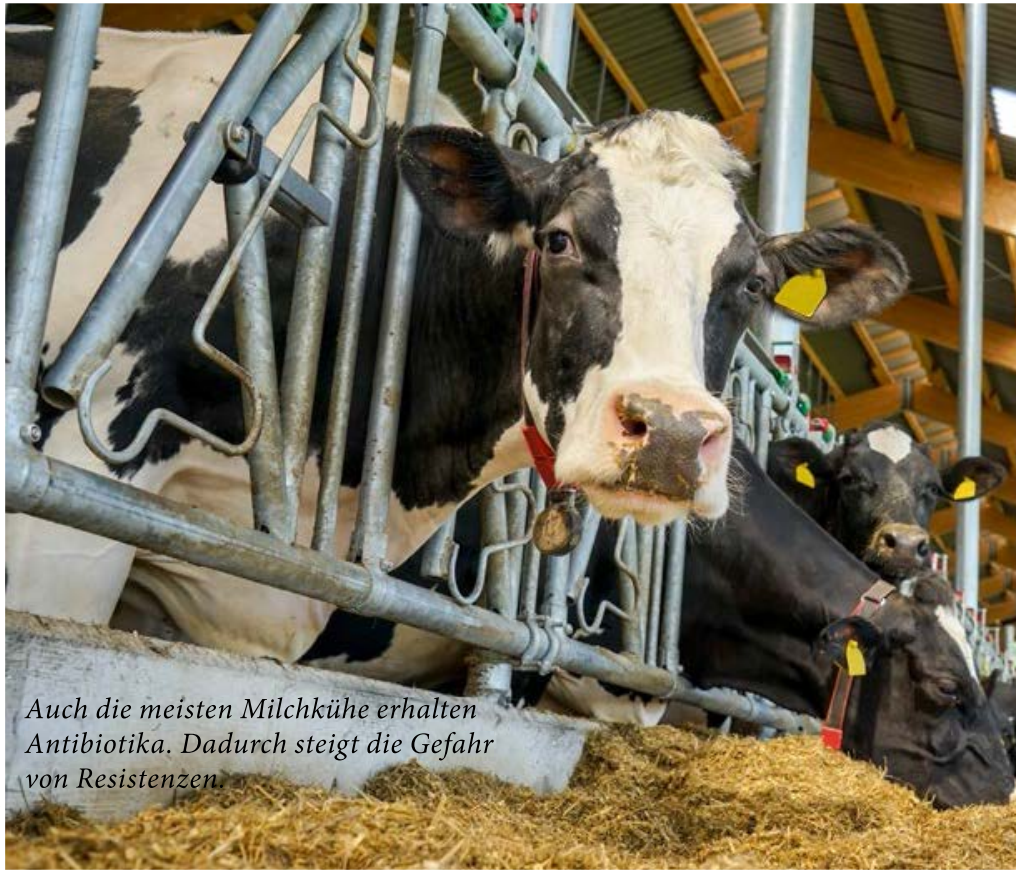

\section{Bald auch in Deutschland: Schockbilder auf Zigarettenschachteln}

Raucher in Deutschland müssen sich bald auf Schockfotos und größere Warnhinweise auf Zigarettenschachteln einstellen. Von Mai 2016 an sollen zwei Drittel der Vorder- und Rückseite von Zigaretten- und Drehtabak-Verpackungen für kombinierte Warnbilder und aufklärende Texte reserviert sein - weit mehr als bisher schon.

Einen entsprechenden Gesetzentwurf von Landwirtschaftsminister Christian Schmidt (CSU) billigte das Bundeskabinett im Dezember 2015 in Berlin. Erzeugnisse, die nach den alten Regelungen bis Mai 2016 hergestellt wurden, können noch ein Jahr lang weiter verkauft werden. Damit wird die nach langem Streit 2014 ausgehandelte EU-Richtlinie für Tabakprodukte auch in deutsches Recht umgesetzt. Die Vorgaben sind klar: Ob krebsbefallene Lungen, faulende Raucherbeine oder geschwärzte Zahnstümpfe - Gruselbilder und abschreckende Warnungen auf einem Großteil der Packungen sollen die Lust am Glimmstängel dämpfen. Auch sollen Aromen, die den Tabakgeschmack überdecken, vom Markt verschwinden - Zigaretten und Drehtabak mit charakteristischen Aromen werden verboten. Kleine Verpackungsgrößen sind für bestimmte Tabakwaren verboten, auch "irreführende Elemente auf Verpackungen“.

Die Grünen warfen der Regierung unterdessen vor, keine Gesamtstrategie zur Reduzierung des Tabakkonsums zu verfolgen. Der Sprecher für Drogen- und Suchtpolitik der Grünen-Fraktion, Harald Terpe, sagte: „Werbebeschränkungen für Tabakprodukte sind längst überfällig." Deutschland sei neben Bulgarien das einzige EU-Land, das Außen- und Kinowerbung für Tabakprodukte immer noch erlaube. „Die Regierung muss sich von den Interessen der Industrie frei machen. Arbeitsplätze und Steuereinnahmen sind kein Argument, wenn es um Menschenleben geht."

$(d p a / j k)$ 